\title{
Acoustic Analysis on the Palatalized Vowels of Modern Mongolian
}

\author{
Sangidkhorloo Bulgantamir \\ The National University of Mongolia, The School of Sciences, Faculty of Humanities, \\ Department of European Studies Mongolia, Ulaanbaatar, Mogolia \\ E-mail: sbulgantamir@yahoo.com
}

Doi:10.7575/aiac.alls.v.6n.6p.107

URL: http://dx.doi.org/10.7575/aiac.alls.v.6n.6p.107
Received: 15/07/2015

Accepted: 04/09/2015

\begin{abstract}
In Modern Mongolian the palatalized vowels [á, $\dot{j}, \dot{0}]$ before palatalized consonants are considered as phoneme allophones according to the most scholars. Nevertheless theses palatalized vowels have the distinctive features what could be proved by the minimal pairs and nowadays this question is open and not profoundly studied. The purpose of this work is to determine the acoustic and articulator features of the vowels preceding the palatalized consonants and the corresponding plain vowels of Modern Mongolian, Khalkha dialect. In the introduction, the definitions on the palatalized vowels and the previous traditional, experimental analysis of the palatalized vowels are discussed. Therefore, in the second section we presented the results of comparison of the short palatalized vowels and the corresponding plain vowels: (1) methods of the experimental study, (2) results of the acoustic features of palatalized and plain vowels. In result of this observation the formants, the length and the pitch of the short palatalized vowels differ more or less in comparison with corresponding plain vowels.
\end{abstract}

Keywords: Mongolian, Khalkha dialect, vowel, palatalized, plain, acoustic

\section{Introduction}

In phonetics, palatalization refers to any articulation involving a movement of the tongue towards the hard palate. Palatalization has phonemic or allophonic in different languages. In Mongolian, the palatalized vowels occur before palatalized consonants and before front vowel [i] in second syllable. In Mongolian the palatalized consonants [ $\mathrm{p}^{\mathrm{hj}}, \mathrm{p}^{\mathrm{j}}, \mathrm{t}^{\mathrm{hj}}$, $\left.\mathrm{t}^{\mathrm{j}}, \mathrm{g}^{\mathrm{j}}, \mathrm{m}^{\mathrm{j}}, \mathrm{n}^{\mathrm{j}}, \mathrm{b}^{\mathrm{j}}, \mathrm{x}^{\mathrm{j}}, \mathrm{r}^{\mathrm{j}}, \mathrm{w}^{\mathrm{j}}\right]$ have contrastive distribution: am (mouth) - am (life); xar (see) - xar (come back home); pot (think) - pot (being); or (overgrowth) - or (invite). But the palatalized vowels are considered phonetic and have complementary distribution (Vandui, 1961; Moomoo, 1979; Luvsanvandan, 1999; Tsoloo, 2008; Nadmid, 1978; Ramstedt,; Vladimirtsov, 1987; Poppe, 1955; Sanjeev, 1959; Svantesson et all., 2005; Puthaval, 2011). But some scientists say the opposite: the palatalized vowels are phonemic while the palatalized consonants are phonetic (Tomortseren, 1970). From the historic phonetics point of view, the vowel [i] in the second syllable influences and palatalizes not only preceding consonant but also initial vowel:

CM (Modern Mongolian) xỏnǐ / xön (sheep) < MM (Middle Mongolian) qoniin <

AM (Ancien Mongolian) qonii < PM (Proto-Mongolian) qoniin

[i] in non initial syllables was reduced and while [i] was lost, the palatalized consonant became phonemic, which influences on preceding pharyngeal vowels. This phenomenon demonstrates the abundance of regressive assimilation in Mongolian. The influence of front vowel like [i] palatal would be strong: high F2 vowels would have the greatest fronting effect on adjacent sounds or neutralize it had become allophonic or phonemic. The Khalkha dialect has seven vowels: $[\mathfrak{e}, \mathrm{\jmath}, \mathrm{v}, \mathrm{e}, \mathrm{o}, \mathrm{u}, \mathrm{i}]$. The non-pharyngeal vowels $[\mathrm{e}, \mathrm{o}, \mathrm{u}]$ never occur before palatalized consonants, but only pharyngeal vowels $[a, \jmath, v]$ suffer the palatalization. In Modern Mongolian the palatalized vowels $[\dot{a}, \dot{j}, \dot{\sigma}]$ are phonetic (allophonic) since they occur only before palatalized consonants. In this study on palatalized vowels, we stick to only phonetic elements of identification, with the exception of phonological pertinence. Of course, the taking into account of palatalization will prove to be especially valuable at the phonological analysis, but it is necessary to identify it first as phonetic facts.

When the pharyngeal vowels $[a, \jmath, v]$ are followed by a palatalized consonant, their pronunciation is changed ${ }^{1}$. Then the result of this study will help them to find solutions to resolve it. The data of investigation may be used on computational phonology, e.g. automatic recognition, text-to-speech synthesis, and then it can be used to improve the software of textto-speech of Mongolian language designated for the deaf people. In this way we try to give a description of the main phonetic features as stress, intensity, pitch and formants.

\footnotetext{
${ }^{1}$ Mongolian as being characterized by a distinction between front vowels and back or pharyngeal vowels. The vowel harmony rules are strict in Mongolian. The vowel $i$ was neutral to vowel harmony, it can occur in either class. These pharyngeal vowels become more closed, centralized and palatalized.
} 
In traditional phonetics many scientists have studied the palatalization of the pharyngeal vowel in Khalkha in phonological and historical perspectives. For example, Academician Luvsanvandan (1999) determined that the place of articulation of the vowels before [i] is in front. Also there may be mentioned researchers Vladimirtsov (1987) who indicated the nuance and the change of their pronunciation under the influence of $[i]$ and Poppe (1955) who compared this change in the different dialects as Ordos, Khalkha, Buriat, Chahar and Kalmyk. Professor S. Moomoo (1979) that defined the phonetic system of Mongolian by experimental means in Russia. Although, he studied only the consonantal palatalization. Juha Janhunen (2003, p.185) divided Mongolic dialects into two groups based on the feature of palatalness of their phonological systems, particularly of consonantal palatalization. These two well-defined groups are palatalization dialects (Khalkha and Chakhar) and umlaut dialects (Khorchin, Kharachin and Juu Uda).

There are few experimental studies on the vocalic palatalization of the Mongolian. Only Svantesson et al., in their studies on the phonology of Mongolian, made the acoustic comparative analysis of the palatalized long vowels [ä: ö: $\ddot{0}:]$ and the diphthongs [ai oi vi], (Svantesson et al., 2006, p.10) concluded that the pronunciation of long and short vowels before the consonants palatalized change considerably and the final part of the vowel is close to $i$.

\section{Acoustic analysis}

\subsection{Methodology of the experimental study}

The source of words for this data is a large dictionary Mongol xelnii delgergui tajlbar tol' published by Mongolian Academy of Science in 2008. Around 54 high-frequency words are chosen and recorded in the phonetic laboratory of Inner Mongolia University in 2011. The instrumental phonetic investigation is based on acoustic data of those isolated monosyllabic words ${ }^{2}$ recorded by a male speaker, S1. In addition, data gathered from two males and a female speaker in order to check the measurements obtained from S1. All the speakers are native and from Mongolia ${ }^{3}$. The recordings were analyzed in the ESPS/Waves+ environment using the speech analysis program Praat 5.2.21 ${ }^{4}$

\subsection{Results}

2.2.1 Vowel length

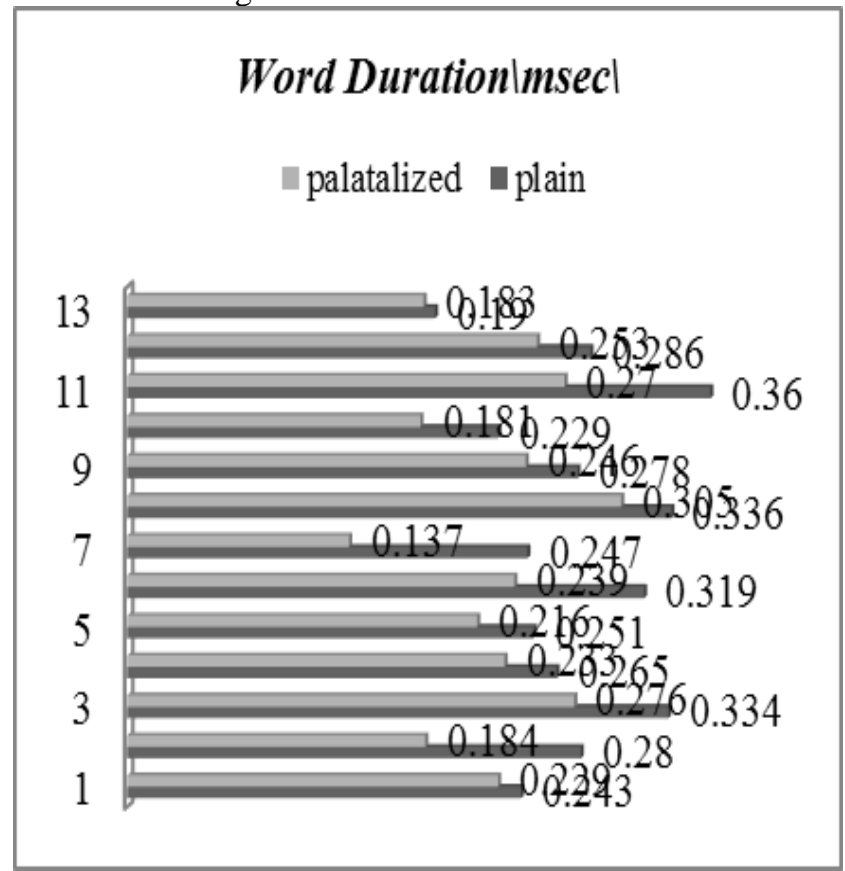

Figure 1. Word duration (ms).

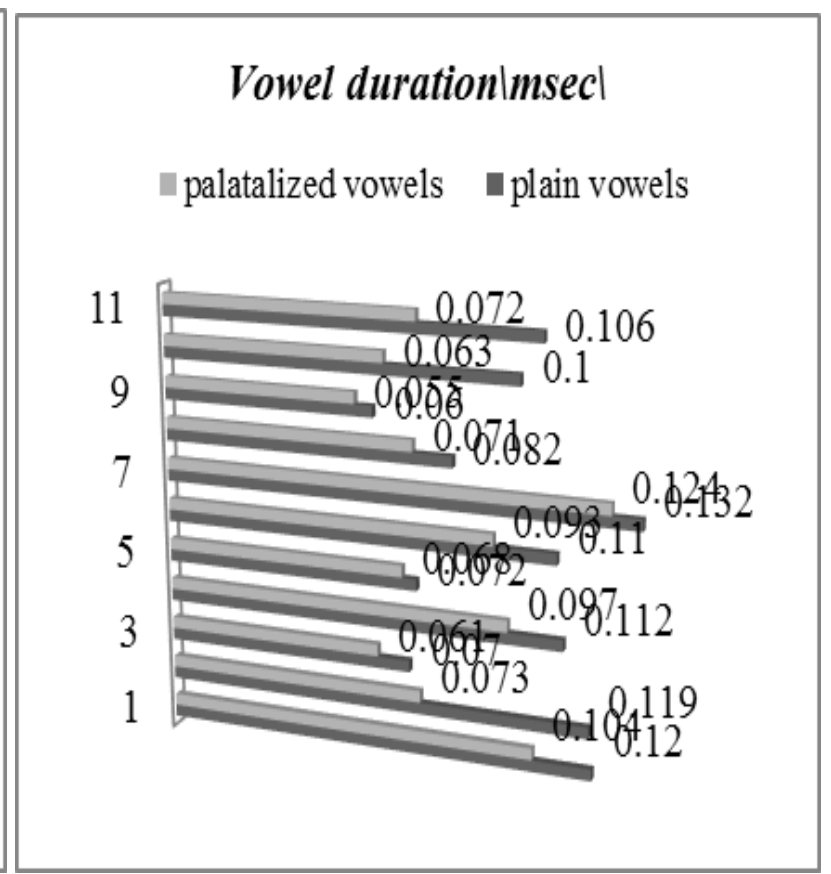

Figure 2. Vowel duration (ms).

In Figure 1, when we compare the duration of the same type words (e.g., VC am / am' and CVC dal / dal'), the duration of the words with palatalized vowel is shorter than of the corresponding words without. We also compared the duration of the palatalized and plain vowels in Figure 2 where it can be concluded that the duration of palatalized vowels may be shorter than their corresponding plain vowels.

2.2.2 F1 and F2

We can see in Figure-3, Figure- 4 that F1 of the palatalized vowel $[\dot{a}, \dot{j}, \dot{\sigma}]$ is decreasing and his F2 is increasing. The parameters here are the average of the all fifty four words. Furthermore when we observe F1 from the final part of the palatalized vowel, it is more closed and front than the rest.

Moreover it should be noted that the disparity between plain [ $\mho]$ and palatalized $[\dot{\mho}]$ is smaller than [a, j]. We discuss it below in the figure 5 .

\footnotetext{
${ }^{2} \mathrm{VC} / \mathrm{CVC}$ type monosyllabic words are chosen.

${ }^{3}$ Speaker 1: D. Naranjargal, m., age 27, khalkha; Speaker 2: A. Bilegsaikhan, m., age 20, khalkha;

Speaker 3: Dz. Enkhbayar, f., age 25, khalkha.

${ }^{4}$ Software was written by Paul Boersma and David Weenink, Professors of Phonetic Sciences in the Institute of Phonetic Sciences of the University of Amsterdam.
} 


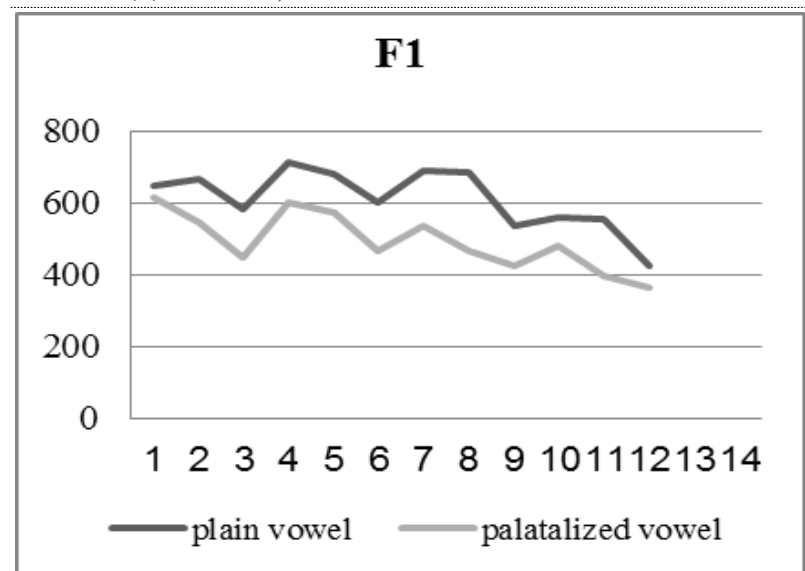

Figure 3. Average F1 (Hz) of the plain and palatalized vowels
F2

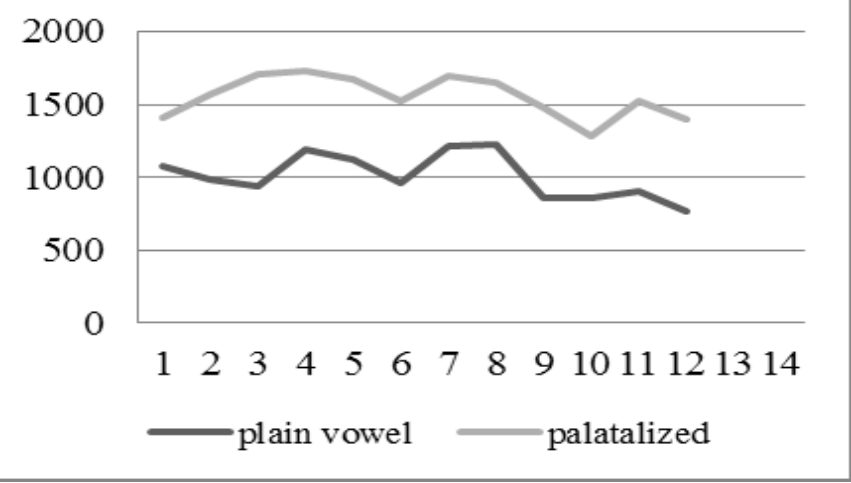

Figure 4. Average F2 (Hz) of the plain and palatalized vowels

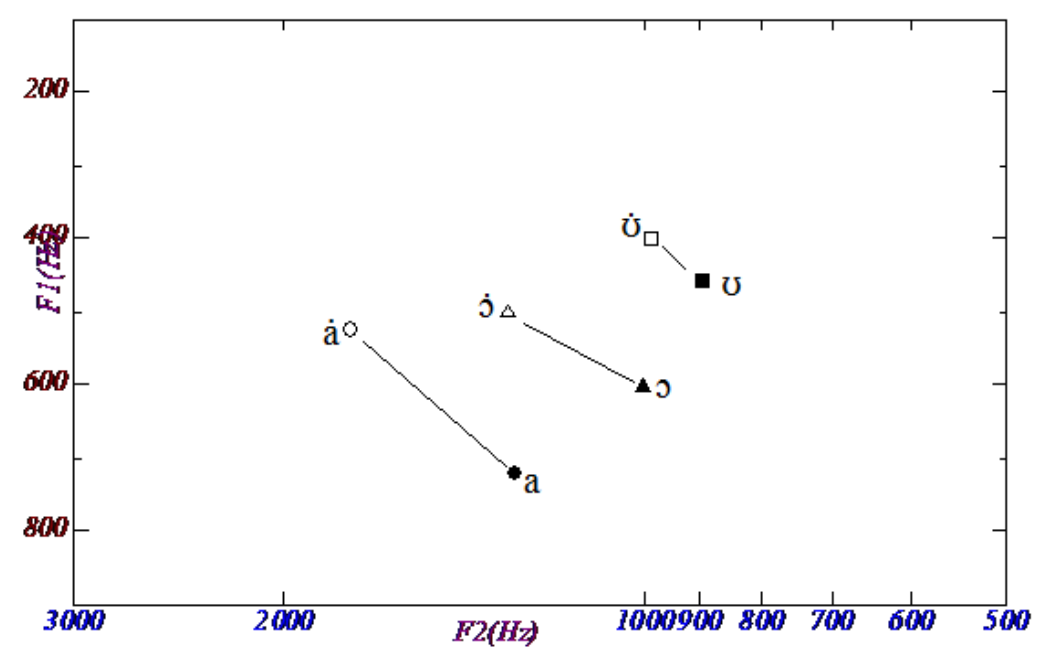

Figure 5. F1-F2 (Hz) of the plain pharyngeal ([a, o, v]) and palatalized ([a, j, $\dot{\jmath}])$ vowels of Mongolian

In Figure 5 we can see the change of every pharyngeal vowel and the difference of change degree between [a், $\dot{j}]$ and

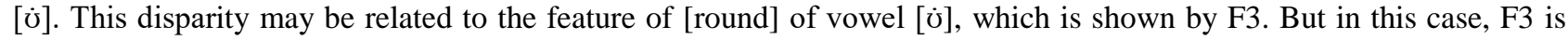
almost equal for [o] $(2531 \mathrm{~Hz})$ and [于] $(2566 \mathrm{~Hz})$. According the acoustic theory of speech production (Fant, 1960), when the constriction is in the middle, labialization leads to the lowest F2 value and the degree of the effect of labialization is larger when the constriction is fronted than when the constriction is back. Hence, [ $\mathrm{J}$ ] is more protruded, back and closed than [0]. When the sound is the most rounded, back and high, it is more insensitive to the palatalization. Moreover, Moosmüller's (2006) study on the aspects of vowel formant interpretation found the following: constriction locations are less sensitive to small displacements, whereas displacements in constriction degree yield monotonous changes in formant frequencies. According to this conclusion, the constriction degree of [à, j,] may be more important than $[\dot{\sigma}]$.

2.2.3 Pitch

The pitch was measured at the beginning, middle and end of the vowels. In the beginning and middle the pitch was almost similar for palatalized and plain vowels. (Figures 6,7)

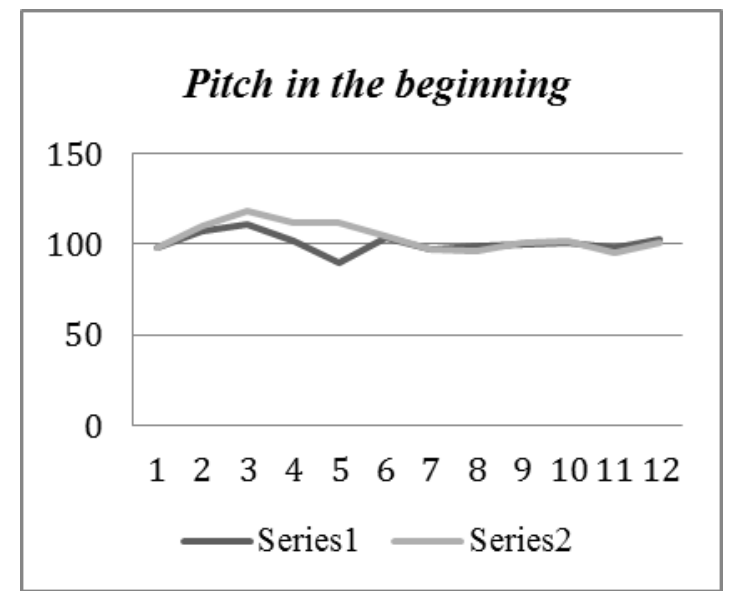

Figure 6. Pitch in the beginning of vowels. Series 1 - corresponding plain vowels; Series 2 - palatalized vowels

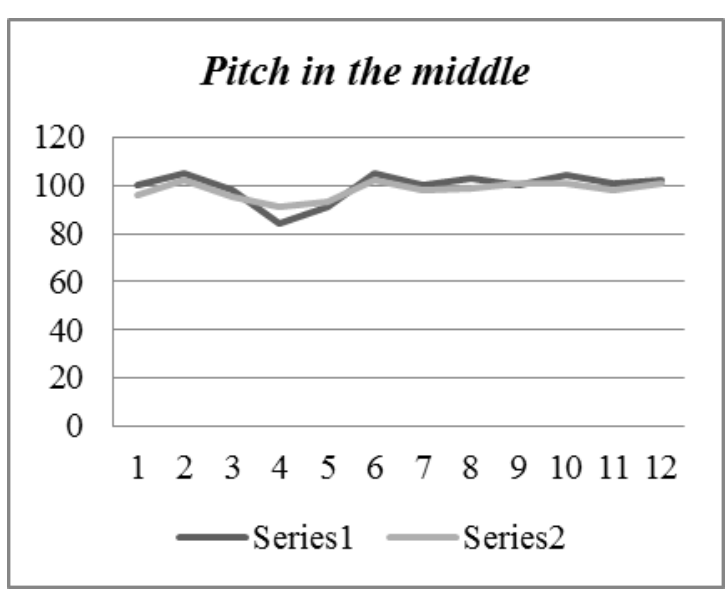

Figure 7. Pitch in the middle of vowels. Series 1 - corresponding plain vowels; Series 2 - palatalized vowels 


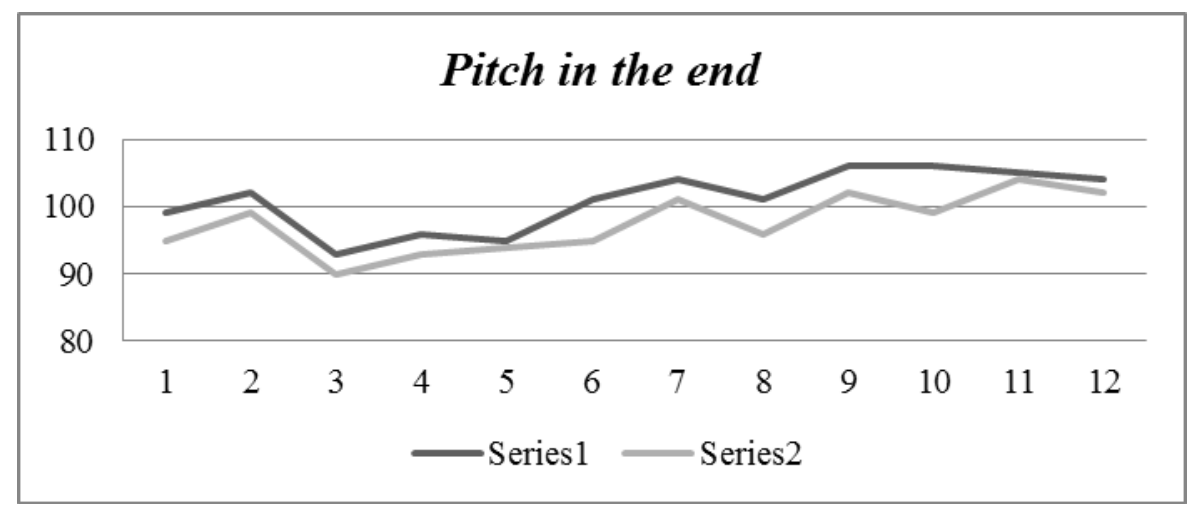

Figure 8. Pitch in the end of vowels.

Series 1 - corresponding plain vowels; Series 2 - palatalized vowels

Those observations approve what Svantesson et al. (2005) assume that when these vowels (long or short) are followed by a palatalized consonant, their pronunciation is changed so that the final part of the vowel becomes more [i]-like. But it is less explicit and less perceptive for short vowels than long vowels.

\section{Conclusion}

- The measurements show the palatalized vowels contrast with the corresponding plain vowels in the isolated monosyllabic words.

- Palatalized vowels are more closed than their plain vowels. E.g., [a] is near low and back vowel, palatalized [ä] is middle or low middle and central vowel; [o] middle and back, palatalized [ó] high middle and central, [ひ] low middle and back, palatalized $[\dot{\mho}]$ near high and back.

- The sound $[\dot{\mathrm{a}}]$ is most influenced by the palatalization while the sound $[\dot{\tilde{\sigma}}]$ is less influenced. As a deduction, we could conclude that when the sound is the most rounded, back and closed, it is more insensitive to the palatalization.

- The length of palatalized vowels is shorter of $30 \%$ than the plain vowels.

\section{References}

Boë, L.J. (1972). Introduction à la phonétique acoustique, Grenoble, France: Travaux de l'Institut de Phonétique de Grenoble.

Bulgantamir, S. (2014). Acoustic analysis of vowels, Acta Mongolica, 14 (385), 19-35.

Crystal, D. (2008). A Dictionary of linguistics and phonetics, Singapore, China: Fabulous Printers Pte.

Fant, G. (1970). Acoustic theory of speech production, with calculations based on X-ray studies of Russian articulations. The Hagues, Netherlands: Mouton.

Janhunen, J. (2003) Mongolic languages, New York, Unites States of America: Routledge.

Ladefoged, P. (2004). Phonetic Data Analysis: An Introduction to Fieldwork and Instrumental Techniques, Malden, Massachusetts: Blackwell Publishing.

Bold, L. (2008). Mongol xelnij delgergui tajlbar tol', Ulaanbaatar, Mongolia: Bembi san.

Möömöö, S. (1979). Mongol xelnij avia züi, Ulaanbaatar, Mongolia: National Press.

Möömöö, S. (2009). Xel shinjlelijn onol, xéréglee, Ulaanbaatar, Mongolia: Admon.

Moosmüller, S. (2006). Some relevant aspects of vowel formant interpretation, Retrieved from https://www.kfs.oeaw.ac.at/publications/MS2006_vowel_formants_GLS65.pdf.

Nadmid, J. (1978). Mongol xelnij örgöltöt üjeijn jerijn bogino egshig, Ulaanbaatar, Mongolia: National Press.

Poppe, N. (1955). Introduction to Mongolian Comparative Studies, Helsinki, Finland: Suomalais-ugrilainen Seura.

Puthuval, S. (2011). Comparative Phonology of Regional Varieties of Mongolian, Retrieved from:

http://courses.washington.edu/lingclas/451/puthuval_draft6.pdf

Sanjaa, J., Nadmid, J. (2008). Mongol xelnij aviazüj ba avialbarzüj, Ulaanbaatar, Mongolia: Press of the University of Education.

Svantesson, J.-O., Tsendina, A., Karlsson, A., Franzén, V. (2005) The phonology of Mongolian, New-York, United States of America: Oxford University Press.

Tömörtseren, J. (1970). Xalxijn ayalguunij egshig avianij tarnaishral, SLL Xel zoxiol sudlal, 4, 143-150.

Tsoloo, J. (1976). Orčin üeijn mongol xèlnii avia züi, Ulaanbaatar, Mongolia.

Vandui, E. (1961). Mongolyn utga zoxiolyn xelnij avialbar (phoneme), SLL Xel zoxiol sudlal, III, 6, 3-17.

Vladimircov, B. Ja. (1989). Sravnitel'naja grammatika mongol'skogo pis'mennogo jazyka i xalxaskogo narecija: vvedenie ifonetika, Moscow, Russia: Nauka. 